\title{
3 Research Square

\section{Oral prednisolone administration in postoperative period improves results of TKA in patient with severe range of motion limitation - a paired outcome study}

\section{Dariusz Grzelecki}

Centrum Medyczne Ksztalcenia Podyplomowego

Jacek Kowalczewski

Centrum Medyczne Ksztalcenia Podyplomowego

Bartłomiej Kordasiewicz

Centrum Medyczne Ksztalcenia Podyplomowego

Marcin Sibinski ( $\square$ sibinskimar@gmail.com )

Medical University of Łódź https://orcid.org/0000-0003-2967-0852

Łukasz Olewnik

Uniwersytet Medyczny w Lodzi

Dariusz Marczak

Centrum Medyczne Ksztalcenia Podyplomowego

\section{Research article}

Keywords: OA - osteoarthritis, RA - rheumatoid arthritis, HTO - high tibial osteotomy, TKA - total knee arthroplasty, total knee replacement

Posted Date: January 23rd, 2020

DOI: https://doi.org/10.21203/rs.2.21723/v1

License: (c) (i) This work is licensed under a Creative Commons Attribution 4.0 International License. Read Full License 


\section{Abstract}

Background One of the most common problems related to total knee arthroplasty (TKA) is postoperatively limited range of motion, especially in the most difficult cases. The aim of the study was to assess the influence of oral use of prednisolone in the postoperative period on the final results in a patient after TKA with severely limited postoperative range of motion. Methods Thirty-two patients (32 knees) with a mean age of 61.2 years were selected from our prospectively-collected data base with severe knee range of motion limitation (rheumatoid arthritis, psoriasis, ankylosing spondylitis, posttraumatic and postoperative osteoarthritis). Prednisolone was administrated in two doses per day (1 mg per kg of body mass) and then the dose was slowly reduced for no more than three months. Results The prednisolone group demonstrated significantly better results one year after the operation than the non-prednisolone group in terms of range of motion (mean extension $0.5^{\circ}$ and $3.0^{\circ} ; p=0.02$, mean flexion $100.1^{\circ}$ and $88^{\circ} ; p=0.01$ ), WOMAC (mean 85.0 and 76.8 points; $p=0.02$ ) and KSS clinical score (mean 86.9 and $81.7 ; p=0.001)$ and KSS functional score (79.3 and 71.0 points; $p=0.01)$. No significant differences were observed between the groups in terms of postoperative systemic and surgical site complications; therefore, no complications could be defined as steroid related. Conclusions The administration of oral prednisolone for a longer postoperative time in patients with severe preoperative range of motion following TKA significantly improves functional results without steroid related complications at one year follow-up.

\section{Introduction}

Total knee arthroplasty (TKA) is an effective procedure for the treatment of osteoarthritis. While satisfactory results can be expected in most standard cases ${ }^{1}$, worse outcomes are often observed for cases characterized by more advanced pathology, including primary or secondary osteoarthritis (OA), e.g. posttraumatic or rheumatoid arthritis, or in patients following previous failed orthopedic procedures. Compromised results are most commonly observed for cases of limitation of knee motion. ${ }^{2}$ Such limitation of preoperative range of motion (ROM) and severe deformity may cause postoperative recurrence of stiffness, limited postoperative ROM and reduced functional and clinical outcomes after TKA. $^{3}$

Jung et al. in their study examined the effect of two postoperative metyloprednisolone treatments on rabbits who had undergone partial synovectomy of the knee (Depo-Medrol, Pfizer, Brussels, Belgium). The histological examination showed inhibition of the development of inflammatory infiltration, which presented as an absence of cellular reactions (giant cells and mononuclear cells) in the synovium and fibrous membrane. No changes in the articular cartilage were observed. ${ }^{4}$ Another study found general steroid therapy to have a very beneficial influence on postoperative knee joint mobility in rabbits after partial synovectomy compared to a control group. ${ }^{5}$ This information, the fact that knee stiffness related to arthrofibrosis decreases patient satisfaction, and that manipulation under anesthesia not always 
achieved satisfactory results, led us to investigate the potential of postoperative oral administration of prednisolone. $^{6}$

No similar studies were found in the available literature examining the influence of steroid therapy on the functional results of TKA. Prednisolone treatment looked promising, and appeared to merit introduction in everyday orthopedic practice; hence, we decided to include the procedure for TKA patients demonstrating the most severe degree of knee pathology, resulting in limited range of motion. It was hypothesized that oral administration of prednisolone could improve postoperative range of motion and thus positively influence the final result without causing significant steroid-related complications.

The aim of the study was to assess the influence of oral prednisolone use in the postoperative period on the final results in patients after TKA characterized by severe limitations in preoperative range of motion.

\section{Material And Methods}

The patents included in the study were selected from a prospectively-collected database of patients treated for TKA in the years 2008 to 2017 in the department specializing in hip and knee arthroplasties. Beginning in 2014, it was decided to include oral prednisolone in treating the cases characterized by the most severe limitation of motion. It was believed that this modification may improve the range of motion and final result of arthroplasty. The inclusion criteria for the examined group were as follows: (1) primary or secondary knee osteoarthritis with severe ROM limitation before TKA - no more than $80^{\circ}$ of the range of motion and $10^{\circ}$ of knee flexion contracture, (2) administration of oral prednisolone twice a day after TKA, (3) informed consent for participation in the study. Patients who had experienced previous septic arthritis, revision TKA, allergy to prednisolone, other contraindications to taking prednisolone (severe osteoporosis, uncontrolled diabetes mellitus, active gastrointestinal ulcers, diverticulitis), lost to follow-up and those who did not agree to participate in the study, were excluded.

Thirty eight consecutive patents underwent TKA and were treated with prednisolone postoperatively. Among them two patients did not agreed to participate in the study, and four were lost to follow-up. After the exclusion process, 32 patients ( 32 knees) were included in the study (prednisolone group). The mean age was 62.6 years (range from 33 to 82, median 63.8) and the mean BMI was $29.94 \mathrm{~kg} / \mathrm{m}^{2}$ (range from 22.19 to 45.91, median 29.28). The demographic and clinical data are presented in Table 1. 
Table 1

Clinical data of two groups of patients, one treated with prednisolone and one without, before TKA and at one year follow-up.

\begin{tabular}{|c|c|c|c|}
\hline & $\begin{array}{l}\text { prednisolone } \\
\text { group }\end{array}$ & non-prednisolone group & $\begin{array}{l}P \\
\text { value }\end{array}$ \\
\hline Sex female/male & $26 / 6$ & $26 / 6$ & \\
\hline Age (years) & 61.2 years (from 33 to 82 ) & $\begin{array}{l}64.0 \text { years (from } 35 \text { to } \\
82 \text { ) }\end{array}$ & 0.3 \\
\hline Weight $(\mathrm{kg})$ & 75.36 (from 54 to 122 ) & 81.65 (from 58 to 117 ) & 0.18 \\
\hline $\mathrm{BMI}\left(\mathrm{kg} / \mathrm{m}^{2}\right)$ & 28.6 (from 22.19 to 45.26 ) & $\begin{array}{l}31.28 \text { (from } 23.23 \text { to } \\
42.91 \text { ) }\end{array}$ & 0.11 \\
\hline Knee extension before TKA & $18.0^{\circ}$ (range from $10^{\circ}$ to $40^{\circ}$ ) & $\begin{array}{l}16.0^{\circ} \text { (range from } 10^{\circ} \text { to } \\
35^{\circ} \text { ) }\end{array}$ & 0.4 \\
\hline Knee flexion before TKA & $69.7^{\circ}$ (range from $40^{\circ}$ to $90^{\circ}$ ) & $\begin{array}{l}66.2^{\circ} \text { (range from } 30^{\circ} \text { to } \\
85^{\circ} \text { ) }\end{array}$ & 0.5 \\
\hline Knee extension after TKA & $0.5^{\circ}$ (range from $0^{\circ}$ to $10^{\circ}$ ) & $3.0^{\circ}$ (range from $0^{\circ}$ to $20^{\circ}$ ) & 0.02 \\
\hline Knee flexion after TKA & $100.1^{\circ}$ (range from $80^{\circ}$ to $130^{\circ}$ ) & $\begin{array}{l}88.0^{\circ} \text { (range from } 40^{\circ} \text { to } \\
130^{\circ} \text { ) }\end{array}$ & 0.01 \\
\hline WOMAC before operation & $\begin{array}{l}51.9 \text { points (range from } 27.4 \text { to } \\
68.9 \text { ) }\end{array}$ & $\begin{array}{l}51.7 \text { (range from } 29.5 \text { to } \\
67.6 \text { ) }\end{array}$ & 0.9 \\
\hline $\begin{array}{l}\text { KSS clinical before } \\
\text { operation }\end{array}$ & 34.8 (range from (-15) to 58 ) & $\begin{array}{l}34.3 \text { (range from (-13) to } \\
53)\end{array}$ & 0.8 \\
\hline $\begin{array}{l}\text { KSS functional before } \\
\text { operation }\end{array}$ & 51.5 (range from 5 to 75 ) & 50.2 (range from 7 to 69 ) & 0.7 \\
\hline Final WOMAC & 85.0 (range from 56.9 to 97 ) & $\begin{array}{l}76.8 \text { (range from } 47.1 \text { to } \\
95.9 \text { ) }\end{array}$ & 0.02 \\
\hline Final KSS clinical & 86.9 (range from 64 to 97 ) & $\begin{array}{l}81.7 \text { (range from } 61 \text { to } \\
95 \text { ) }\end{array}$ & 0.001 \\
\hline Final KSS functional & 79.3 (range from 55 to 100 ) & $\begin{array}{l}71.0 \text { (range from } 54 \text { to } \\
95 \text { ) }\end{array}$ & 0.01 \\
\hline
\end{tabular}

Prednisolone (Encorton, Polfa S.A., Pabianice, Poland) was administrated in two doses per day, morning and afternoon dose ( $1 \mathrm{mg}$ per $\mathrm{kg}$ of body mass, maximum dose $90 \mathrm{mg}$ per day) from the first postoperative day (total dose from $55 \mathrm{mg}$ to $90 \mathrm{mg}$ ). Every third day the dose was reduced by $5 \mathrm{mg}$, once from the morning dose and once from the afternoon dose. The dose was reduced to zero, or to the dose prescribed to patients before the operation (rheumatoid patients). The duration of treatment took no more than three months. 
Patients from the study group were matched with patients who did not receive prednisolone administration and were operated before 2014 (control group, non-prednisolone group). The patients were matched in terms of gender, etiology (primary, postoperative, RA OA), range of motion before operation $+/-10^{\circ}$ (but no more than $80^{\circ}$ of the range of motion and $10^{\circ}$ of knee flexion contracture), type of deformity (varus, valgus or neutral) and age $+/$ - two years.

Pre-operative planning was performed in every case with the use of Orthoview orthopedic digital preoperative planning software. The software allowed an assessment of whether limb axis correction could be performed only by bone cuts. The surgeon assessed the possibility of soft tissue balancing, deformation severity, quality of posterior capsule and collateral ligaments. The age, weight and activity level of the patients were also taken into consideration when choosing the type of implant. Most of the patients in the analyzed cohort required standard condylar implants, with or without a stem. Older, obese and inactive patients were more likely to receive stemmed condylar or semi-constrained knee implants; however, the final decision was made intraoperatively with regard to knee stability and bone quality. If a full release of the medial collateral ligament was necessary, or severe joint destruction with insufficient collateral ligaments was noted that made joint balancing impossible, a constrained rotating-hinge implant was chosen. Additional reconstruction materials (augments and cones) were used for bone loss management. Information regarding the type of used implant and etiology are presented in Table 2. 
Table 2

Information regarding etiology, type of deformity and type of implant (Stryker, USA) used for TKA

\begin{tabular}{|lll|}
\hline & Prednisolone & Non-prednisolone \\
\hline Number of patients & 32 & 32 \\
\hline Type of THA & 11 & 9 \\
\hline Condylar & 13 & 17 \\
\hline Condylar with tibial stem & 6 & 4 \\
\hline Semi constrained & 2 & 2 \\
\hline Constrained (rotating-hinge) & & \\
\hline Type of deformity & 14 & 14 \\
\hline Varus & 11 & 11 \\
\hline Valgus & 7 & 7 \\
\hline neutral & & 9 \\
\hline Etiology & 9 & 13 \\
\hline Primary OA & 13 & 1 \\
\hline RA & 1 & 1 \\
\hline Psoriasis & 1 & 5 \\
\hline Ankylosing spondylitis & 5 & 3 \\
\hline OA after tibia or femur fractures & 3 & \\
\hline OA after HTO & - high tibial osteotomy, TKA - total knee \\
\hline OA - osteoarthritis, RA - rheumatoid arthritis, HTO & & \\
\hline arthroplasty & & \\
\hline
\end{tabular}

All operations were performed by one surgeon, the senior author of the study, with the use of tourniquet through the whole procedure. The mid-line incision and medial para-patellar approach was used for varus and neutral knees, and a lateral approach was used for valgus knees. For severe contractures, extensive exposures including quadriceps snip and/or tibial tubercule osteotomy were performed. No patient underwent metalwork removal during TKA. In all cases, proper patella tracking, full extension and knee flexion were checked by the end of surgery.

For patients who underwent multiple procedures on the operated limb, restorable bone graft substitutes with antibiotic beads (Herafill beads G, Heraeus Medical, Wehrheim, Germany) were inserted to medullary 
canals as an antibacterial prophylaxis. Allografts were not implanted, but BoneSave (Stryker, USA) bone substitute was needed in one case.

Radiological analysis was used to assess the quality of fixation of the components according to the Knee Society Roentgenographic Evaluation and Scoring System. ${ }^{7}$ The Knee Society Clinical Rating System $(\mathrm{KSS})^{8}$ and Western Ontario and McMaster Universities Arthritis Index (WOMAC) ${ }^{9}$ were used for clinical assessment. Clinical data including preoperative and final follow-up range of motion, septic complications, complications related to prednisolone application, including wound healing problems, were analyzed. The data from the first preoperative assessment and those from a one-year follow-up visit were used for calculations.

Informed consent was obtained from patients for participation in the study. This study was performed in accordance with the ethical standards laid down in the 1964 Declaration of Helsinki. This study was approved by Bioethics Committee of the institution of the first author of the study (30/PB/2018).

\section{Statistical analysis.}

Statistica version 13.1 (Dell Inc 2016) was used for statistical analysis. Levene's test was used to test the normality of distribution. Student's T-test for dependent samples was used to compare demographical data, WOMAC score, functional and clinical KSS score, and range of motion. A p-value $<0.05$ was considered to be significant.

\section{Results}

Both groups (prednisolone and none-prednisolone) were matched, so were comparable in terms of age, gender, type of pathology and deformity (Table 1). All patients demonstrated significantly better results one year after operation in terms of range of motion, WOMAC and KSS score compared to preoperative values. For the prednisolone and non-prednisolone group at the last follow-up, the mean extension was $0.5^{\circ}$ and $3.0^{\circ}$ and the mean flexion $100.1^{\circ}$ and $88^{\circ}(p=0.02, p=0.01)$ respectively. Mean WOMAC score at one year was found to be 85.0 points for prednisolone and 76.8 points for the non-prednisolone group ( $p$ $=0.02$ ). Both groups demonstrated better clinical and functional KSS scores at one year (mean KSS clinical was 86.9 for prednisolone and 81.7 for non-prednisolone; mean KSS functional score was 79.3 points for prednisolone and 71.0 points for non-prednisolone $(p=0.001, p=0.01)$ (Table 1).

No complications were found that could be defined as steroid related. The period of analyzed drug administration was relatively short, so no systemic complications were reported by any of the patients. Radiographs performed at the one-year follow-up showed no signs of loosening. There were no steroid septic complications in either the study or control group (Table 3). One patient from the prednisolone group had PJI, most probably related to steroid injections given in a previous orthopedic center, and he did not agree for another operation. Also, one patient from the non-prednisolone controls developed PJI and required two-stage revision TKA. All patients with wound healing problems demonstrated portable 
negative pressure wound therapy and all but one were treated successfully. The remaining patient required additional surgical intervention and skin flap transfer.

Table 3

Complications following TKA in the prednisolone and nonprednisolone groups

\begin{tabular}{|lll|}
\hline & Prednisolone & Non-prednisolone \\
\hline Periprosthetic joint infection & 1 & 1 \\
\hline Wound healing problems & 2 & 2 \\
\hline Arthrofibrosis & 1 & 2 \\
\hline Redression & 1 & 2 \\
\hline Rewision TKA & 0 & 1 \\
\hline
\end{tabular}

\section{Discussion}

The use of steroids in patients undergoing total knee and hip arthroplasties has been extensively described in the literature. A perioperative, systemic single steroid injection has been shown to be effective in the reduction of postoperative pain, postoperative opioid consumption, hospital stay, reduction of postoperative vomiting and nausea. ${ }^{10-12}$ Some authors report that a perioperative, periarticular single-dose injection can improve short-term functional recovery and clinical parameters, resulting in better outcomes without any increase in perioperative complications. ${ }^{13-16}$ However, these studies examine short-term administration of steroids and the short-term effects observed during a hospital stay. In contrast, our present study examines the results of postoperative oral prednisolone administration in patients, one year after TKA. Oral application was prescribed depending on the patient weight and continued for up to three months in all cases, regardless of the range of motion limitation. In this case, the main aim of prednisolone administration was not to reduce the postoperative side effects of anesthesia, but gain better functional results and motion: secondary to persistent pain and loss of function, knee stiffness related to joint arthrofibrosis following primary TKA can lead to unsatisfactory patient outcomes. This may require intensive rehabilitation, manipulation under anesthesia (MUA) or even revision knee arthroplasty. ${ }^{6}$ No similar studies were found by us in the present literature.

Our results indicate that patients who received prednisolone as postoperative therapy gained better outcomes than the controls, as indicated by WOMAC, clinical and functional KSS and ROM scores. This improvement may be associated with the analgesic effect known to be provided by glucocorticoids, which acts by inhibiting peripheral phospholipase; this effect will reduce anxiety and allow better rehabilitation. In addition, steroids have also been found to have anti-inflammatory effects. ${ }^{4,5,10-12}$ 
In properly performed TKA postoperative joint contracture is related to the development of intra-articular adhesions, created on the basis of a hematoma, and related to an excessive fibrosis within the articular capsule. ${ }^{4}$ Glucocorticoids prevent fibroblast migration, as well as their growth and development; they are also known to inhibit the synthesis of collagen. It is possible that glucocorticoids such as prednisolone may act through influencing fibroblast activity, as well as collagen production or degradation, judging from periarticular and intra-articular adhesions, excessive fibroplasia of the cicatrix. ${ }^{4}$

Interest has recently grown in the perioperative systemic use of steroids in patients undergoing total knee and hip replacement, with a number of well-designed studies, systematic reviews and metanalyses being published. ${ }^{6,11,17}$ However it is difficult to make comparisons between studies due to the variation in the doses and types of steroids used, as well as the timing of administration. A meta-analysis of randomized trials by Yue et al. confirmed that steroid injections offer positive benefits in terms of lower incidence of postoperative nausea and vomiting, as well as reduction of acute postoperative pain, hospital stay, without significant complications or adverse events. They also note an improvement in early functional rehabilitation and inflammation control. The examined studies focused on perioperative systemic administration of steroids with the aim of shortening recovery time in total knee and hip arthroplasty; medications were given before the operation with one or two doses possibly being given every eight hours following the operation. ${ }^{11,12,17}$

Lower levels of IL- 6 have been found within 24 hours following the operation ${ }^{18}$, and lower CRP concentrations have been recorded in steroid groups in the 24 hours following THA. ${ }^{12}$ In addition, lower IL-6 levels have were also observed 12 hours after operation. ${ }^{19}$ Perioperative systemic steroid administration is associated with reduction of pain shortly after operation, with the effects being well defined within the first 24 hours, following which, the differences disappear. ${ }^{12,19}$ Another metanalysis of three studies confirmed lower opioid consumption within 48 hours of the operation following steroid administration. ${ }^{11}$ Metanalyses comparing steroid and non-steroid groups clearly show a low risk of complications such as superficial or deep infection, delayed wound healing, ONFH, venous thromboembolic events and pruritus, and that this risk is similar in both groups. ${ }^{11,17}$

It would be interesting to investigate whether steroid administration could improve the rehabilitation process. Some studies have shown that, similar to pain reduction, administration also has a positive effect on very early functional outcomes: the effects are seen mostly within the first postoperative days, before discharge from the hospital ${ }^{10,12}$, however, no significant difference can be seen between steroid and non-steroid groups at six weeks and one year following the procedure. ${ }^{20}$ Hence it appears to be logical to prolong steroid administration to gain better rehabilitation results, as confirmed by our research.

Steroids can also be administered through periarticular steroid injections; these can be supplemented with local anesthetics and epinephrine to reduce post-operative pain and inflammation. This route of administration also improves short-term functional recovery and clinical parameters, resulting in better outcomes for patients without being associated with steroid-related complications. ${ }^{16}$ The short term, 
local pain-relieving effect of this kind of multimodal cocktail has been confirmed by other authors ${ }^{13,15}$, for example, a metanalysis by Cui et al. confirms that steroid injection in TKA/THA provides short-term advantages in pain relief and antiemetic effects. ${ }^{14}$

There are some limitations of the study. The first is that it uses a relatively small group of patients; however, the study is focused on very specific rare cases characterized by severe, advanced osteoarthritis which is primary, secondary or related to autoimmunological diseases. Also, as the material was collected in a center specializing in hip and knee surgery, it would be difficult to collect a larger sample. The second limitation is related to heterogeneity of the prednisolone group: knee pathology comprises a broad spectrum etiologies and deformities that require the use of implants with an adequate level of constraints. The effect of this heterogeneity was reduced as much as possible by matching individual patients from the study group with similar ones from the control group with regard to gender, etiology, range of motion before operation and type of deformity. The third limitation of the study is variety of implant used, what was dependent on bone defects and ligamentous stability. Finally, the fourth limitation is related to the fact that patients from both groups were operated in different time periods: prednisolone treatments began in 2014, and the patients from control group were treated before this period; hence, this can be regarded as a historical group.

\section{Conclusions.}

The literature includes a number of well-designed studies with an evidence base that strongly supports the use of pre- and perioperative administration of local and systemic steroids. 6,11,17 Glucocorticoids reduce the postoperative side effects of anesthesia, reduce pain and the need for painkillers, improve ROM and shorten the length of hospital stay. Our findings also demonstrate that longer-term administration of oral prednisolone following TKA for patients with severe preoperative range of motion significantly improves functional results without the presence of steroid-related complications at one year follow-up.

\section{Declarations}

\section{Ethics approval and consent to participate}

The protocol of the study was accepted by Bioethics Committee of our institution (resolution $(30 / \mathrm{PB} / 2018))$

\section{Consent for publication}

Informed consent was signed by all patients participating in the study

\section{Availability of data and materials}


The datasets used and/or analysed during the current study are available from the first author on reasonable request.

\section{Competing interests}

All authors declare no competing interest

\section{Funding}

This research did not receive any specific grant from funding agencies in the public, commercial, or notfor-profit sectors

\section{Authors' Contributions}

$D G, J K, K B, M S, Ł O, D M$ designed the research, developed the concept of the article, acquired the data and revised it critically for important intellectual content. MS, DG, JK analyzed the data and performed statistical analyses. MS, KB, ŁO, DM contributed to interpretation of data. MS, JK drafted the manuscript. All authors read and approved the final manuscript. All aurhors agreed both to be personally accountable for the author's own contributions and to ensure that questions related to the accuracy or integrity of any part of the work

\section{Acknowledgements}

NONE

\section{References}

1. Jabłoński J, Sibiński M, Polguj M, Kowalczewski J, Marczak D Faflik $Ł$, Jabłońska D. The Influence of Implant Position on Final Clinical Outcome and Gait Analysis after Total Knee Arthroplasty. J Knee Surg. 2018;32:891-6.

2. Marczak D, Synder M, Sibiński M, Okoń T, Kowalczewski J. One-stage total knee arthroplasty with pre-existing fracture deformity: post-fracture total knee arthroplasty. J Arthroplasty. 2014;29:2104-8.

3. Lee SA, Kang SB, Chang CB, et al. Does the severity or cause of preoperative stiffness affect the clinical results and range of motion after total knee arthroplasty? PLoS One. 2018;13:e0205168.

4. Jung L, Wagner T, Mazurkiewicz M, Skopińska-Różewska E. The effect of methylprednisolone on the morphology of rabbit knee joint after partial synovectomy. Central European Journal of Immunology. 2008;33:176-8.

5. Jung L, Skorupski M, Szpechciński A, Skopińska-Różewska E. Beneficial effect of methylprednisolone on the postoperative function of rabbit knee. Central European Journal of Immunology. 2008;33:172-5.

6. Gu A, Michalak AJ, Cohen JS, Almeida ND, McLawhorn AS, Sculco PK. Efficacy of Manipulation Under Anesthesia for Stiffness Following Total Knee Arthroplasty: A Systematic Review. J 
Arthroplasty. 2018;33:1598-1605.

7. Ewald $F$. The Knee Society total knee arthroplasty roentgenographic evaluation and scoring system. Clin Orthop. 1989;248:9-12.

8. Insall JN, Dorr LD, Scott RD, Scott WN. Rationale of the Knee Society clinical rating system. Clin Orthop Relat Res. 1989;(248):13.

9. Klässbo M, Larsson E, Mannevik E. Hip disability and osteoarthritis outcome score. An extension of the Western Ontario and McMaster Universities Osteoarthritis Index. Scand J Rheumatol. 2003;32: 46-51.

10. Backes JR, Bentley JC, Politi JR, Chambers BT. Dexamethasone reduces length of hospitalization and improves postoperative pain and nausea after total joint arthroplasty: a prospective, randomized controlled trial. J Arthroplasty. 2013;28 Suppl:11-7.

11. Fan ZR, Ma J, Ma XL, Wang Y, Sun L, Wang Y, Dong BC. The efficacy of dexamethasone on pain and recovery after total hip arthroplasty: A systematic review and meta-analysis of randomized controlled trials. Medicine (Baltimore). 2018;97:e0100.

12. Lunn TH, Andersen LØ, Kristensen BB, Husted H, Gaarn-Larsen L, Bandholm T, et al. Effect of highdose preoperative methylprednisolone on recovery after total hip arthroplasty: a randomized, doubleblind, placebo-controlled trial. Br J Anaesth. 2013;110:66-73.

13. Chai X, Liu H, You C, Wang C. Efficacy of Additional Corticosteroid in a Multimodal Cocktail for Postoperative Analgesia Following Total Knee Arthroplasty: A Meta-Analysis of Randomized Controlled Trials. Pain Pract. 2019;19:316-27.

14. Cui Z, Liu X, Teng Y, Jiang J, Wang J, Xia Y. The efficacy of steroid injection in total knee or hip arthroplasty. Knee Surg Sports Traumatol Arthrosc. 2015;23:2306-14.

15. Kwon SK, Yang IH, Bai SJ, Han CD. Periarticular injection with corticosteroid has an additional pain management effect in total knee arthroplasty. Yonsei Med J. 2014;55(2):493-8.

16. Ng YC, Lo NN, Yang KY, Chia SL, Chong HC, Yeo SJ. Effects of periarticular steroid injection on knee function and the inflammatory response following Unicondylar Knee Arthroplasty. Knee Surg Sports Traumatol Arthrosc. 2011;19:60-5.

17. Yue C, Wei R, Liu Y. Perioperative systemic steroid for rapid recovery in total knee and hip arthroplasty: a systematic review and meta-analysis of randomized trials. J Orthop Surg Res. 2017;12:100.

18. Sculco PK, McLawhorn AS, Desai N, Su EP, Padgett DE, Jules-Elysee K. The effect of perioperative corticosteroids in total hip arthroplasty: a prospective double-blind placebo controlled pilot study. J Arthroplasty. 2016;31:1208-12.

19. Jules-Elysee KM, Wilfred SE, Memtsoudis SG, Kim DH, YaDeau JT, Urban MK, et al. Steroid modulation of cytokine release and desmosine levels in bilateral total knee replacement: a prospective, double-blind, randomized controlled trial. J Bone Joint Surg Am. 2012;94:2120-7.

20. Bergeron SG, Kardash KJ, Huk OL, Zukor DJ, Antoniou J. Perioperative dexamethasone does not affect functional outcome in total hip arthroplasty. Clin Orthop Relat Res. 2009;467:1463-7. 